\title{
Determination of Key Hydrocarbon Autoxidation Products By Fluorescence
}

\author{
Ron Shah \& Derek A. Pratt* \\ Department of Chemistry and Biomolecular Sciences University of Ottawa, Ottawa, Canada K1N 6N5 \\ dpratt@uottawa.ca \\ Supporting Information
}

\section{Table of Contents}

Reactivity of Probe 2 with Palmitic Acid and Tetralin Hydroperoxide ......................S1

Reactivity of Probe 1 with Palmitic Acid and Tetralin Hydroperoxide .....................S2

Hydroperoxide and Acid Concentration Determined using Probes 1 and 5

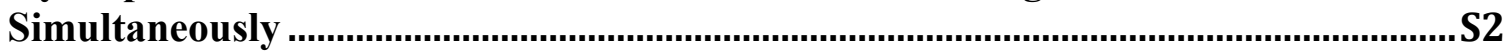

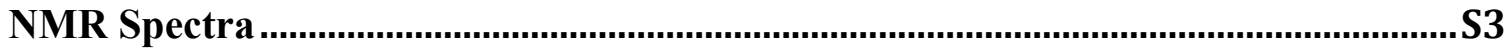

Reactivity of Probe 2 with Palmitic Acid and Tetralin Hydroperoxide

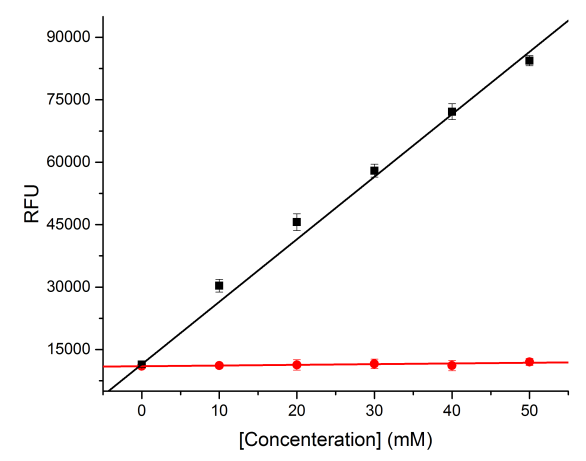

Figure S1. Increase in fluorescence of probe $\mathbf{2}$ as a function of an increasing concentration of either palmitic acid (घ) or tetralin hydroperoxide (๑). 


\section{Reactivity of Probe 1 with Palmitic Acid and Tetralin Hydroperoxide}

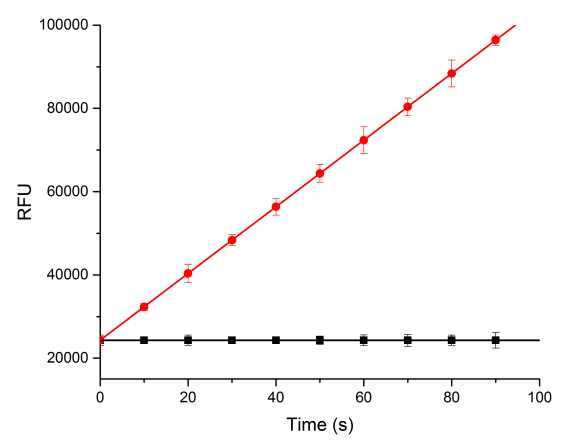

Figure S2. Increase in fluorescence of probe $\mathbf{1}$ as a function of time in the presence of either $20 \mathrm{mM}$ palmitic acid ( $\bullet$ ) or 20mM tetralin hydroperoxide (๑).

\section{Hydroperoxide and Acid Concentration Determined using Probes 1 and 5 Simultaneously}
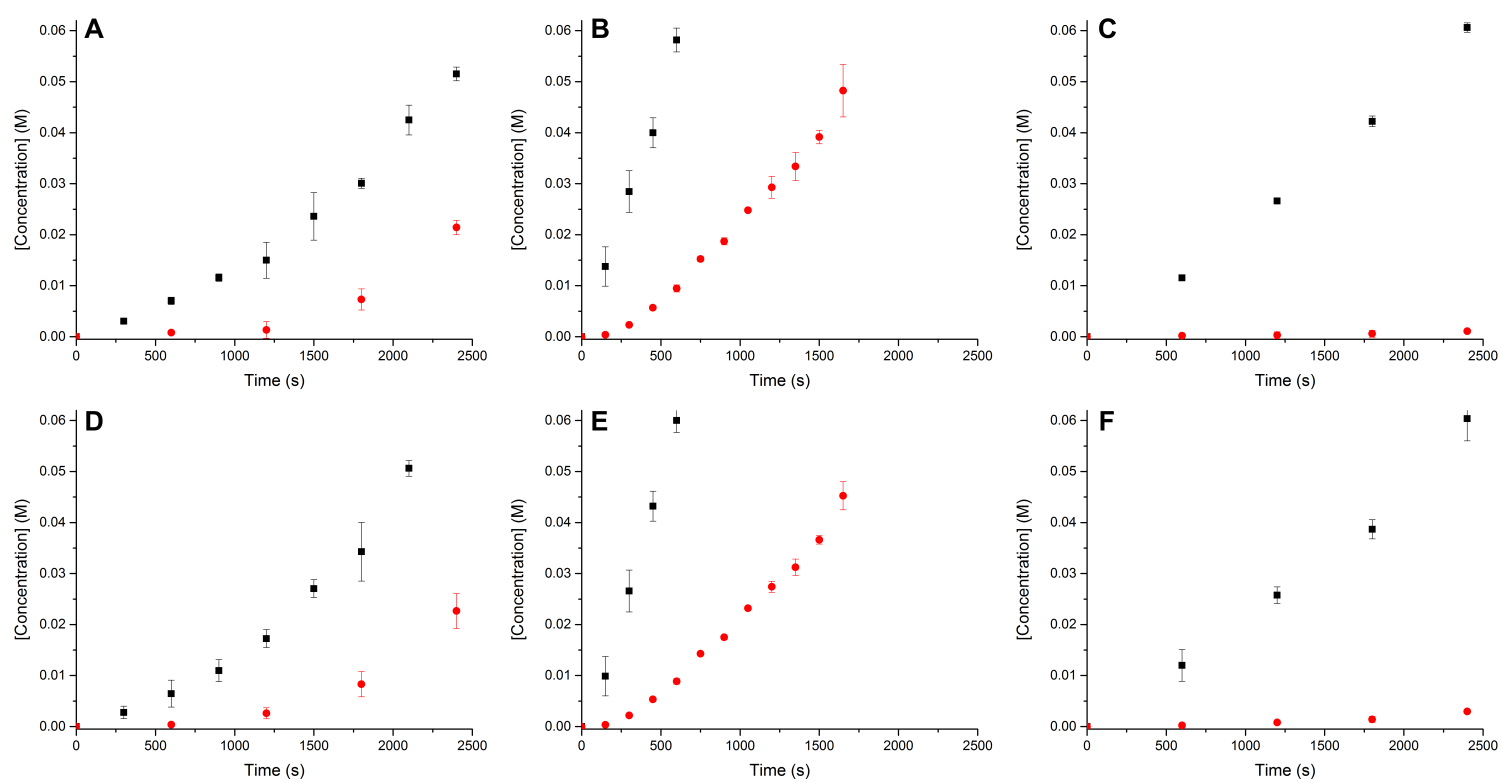

Figure S4. (A-C) Formation of hydroperoxides $(\bullet)$ and acids $(\bullet)$ in the initial stages $(<2 \%$ conversion) of the autoxidation of $n$-hexadecane, a API Group III base oil and 1-hexadecene respectively using probes 1 and 2 separately. (D-E) Formation of hydroperoxides $(\bullet)$ and acids $(\bullet)$ in the initial stages $(<2 \%$ conversion) of the autoxidation of $n$-hexadecane, a API Group III base oil and 1-hexadecene respectively using probes $\mathbf{1}$ and $\mathbf{5}$ simultaneously 
NMR Spectra

గ人<smiles>COc1ccc2cc(C)c(=O)oc2c1</smiles>
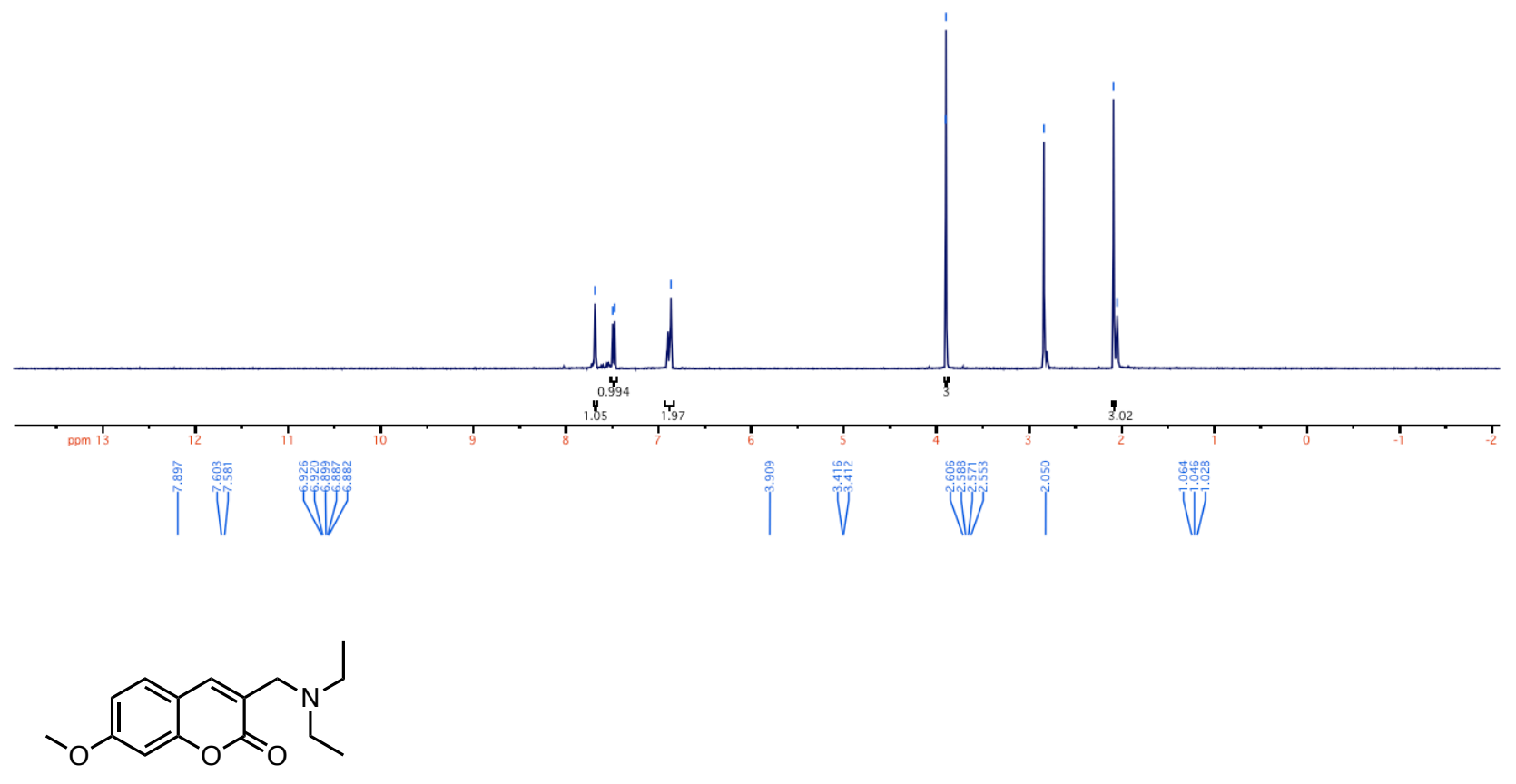

2

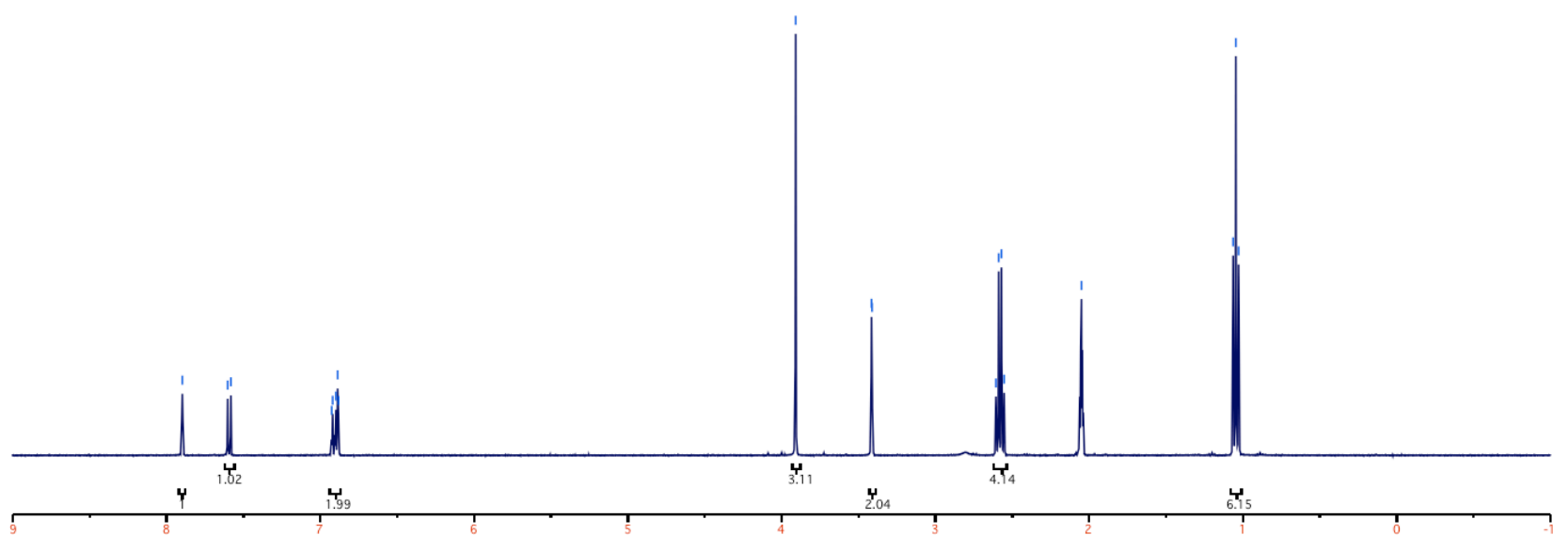




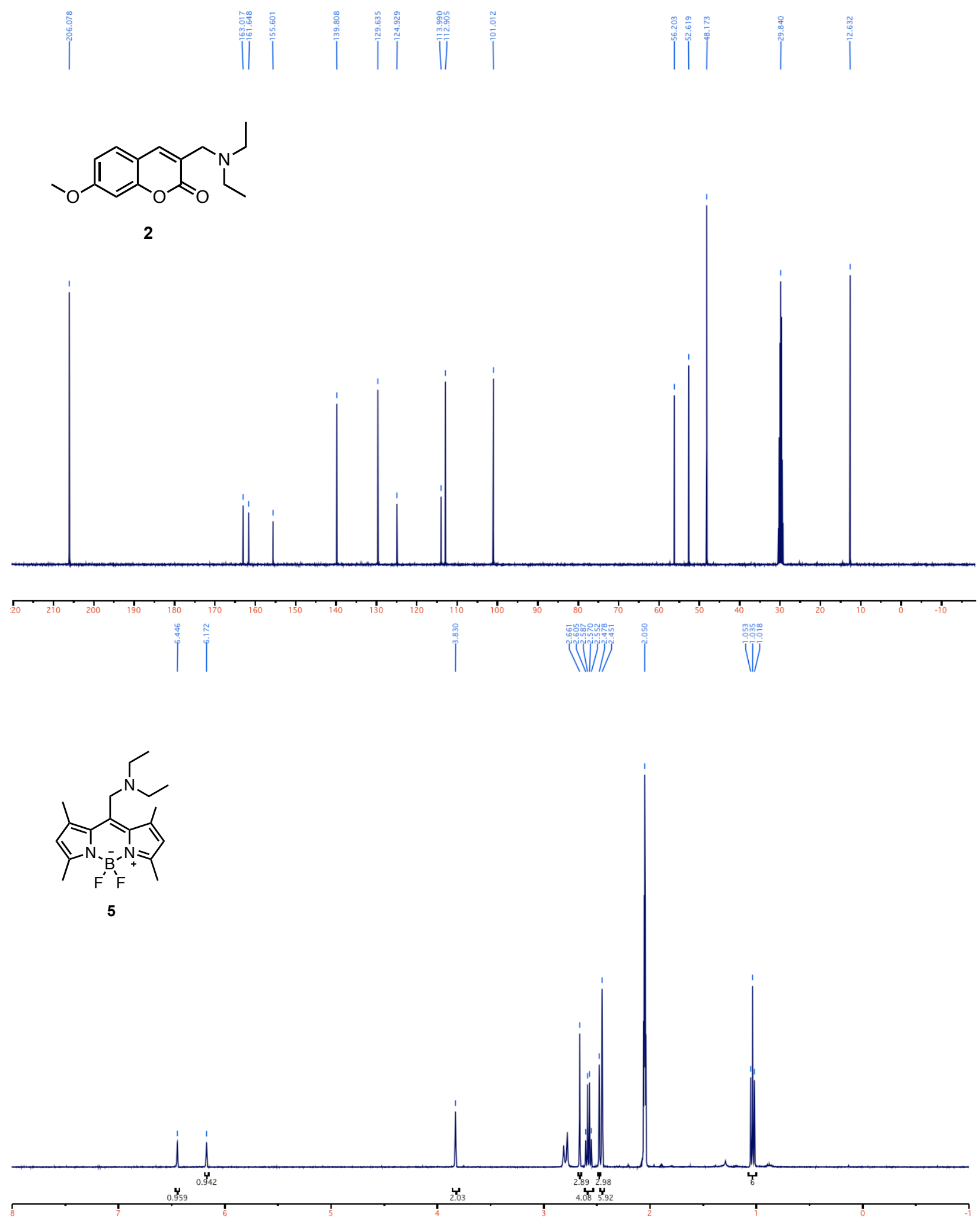




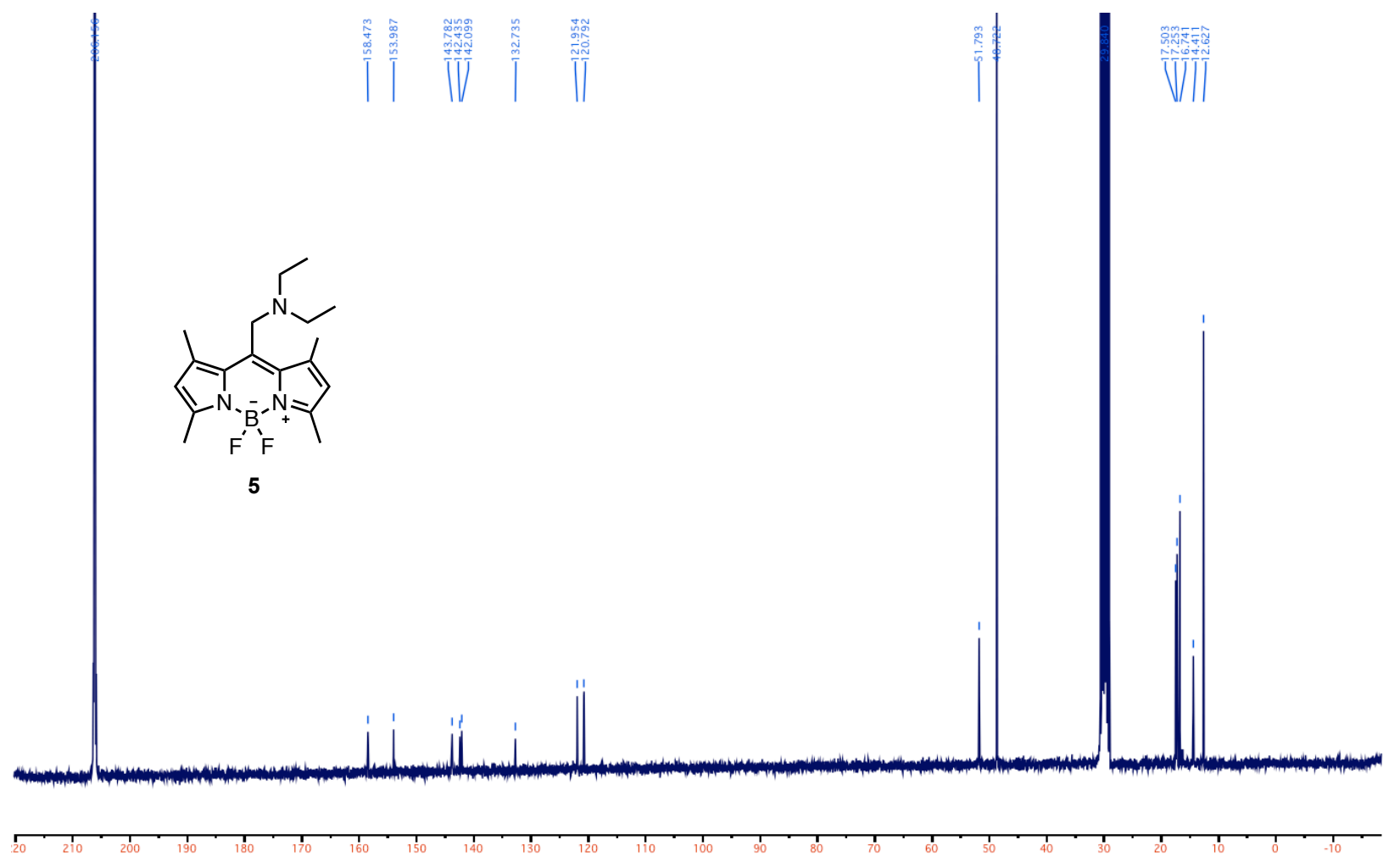

